\title{
Macrophage uptake switches on OCT contrast of superparamagnetic nanoparticles for imaging of atherosclerotic plaques
}

This article was published in the following Dove Press journal: International Journal of Nanomedicine

\author{
Angela Ariza de \\ Schellenberger ${ }^{1, *}$ \\ Wolfram C Poller ${ }^{2, *}$ \\ Verena Stangl ${ }^{2}$ \\ Ulf Landmesser ${ }^{3}$ \\ Eyk Schellenberger ${ }^{1}$ \\ 'Department of Radiology, \\ Charité-Universitätsmedizin \\ Berlin, Germany; ${ }^{2}$ Department of \\ Interventional Cardiology, Charité- \\ Universitätsmedizin Berlin, Germany; \\ ${ }^{3}$ Department of Cardiology, Charité- \\ Universitätsmedizin Berlin, Berlin \\ Institute of Health (BIH) and \\ Deutsches Zentrum für Herz- \\ Kreislaufforschung (DZHK), \\ Berlin, Germany \\ *These authors contributed equally \\ to this work
}

Background: Optical coherence tomography (OCT) is an intravascular, high-resolution imaging technique that is used to characterize atherosclerotic plaques. However, the identification of macrophages as important markers of inflammation and plaque vulnerability remains difficult. Here, we investigate whether the uptake of very small iron oxide particles (VSOP) in macrophages, that cluster in phagolysosomes and allow high-quality magnetic resonance imaging (MRI) of atherosclerotic plaques, and uptake of ferumoxytol nanoparticles enhance detection of macrophages by OCT.

Materials and methods: RAW 264.7 macrophage cells were incubated with VSOP (1 and $2 \mathrm{mM} \mathrm{Fe})$ that have been clinically tested and ferumoxytol $(8.9 \mathrm{mM} \mathrm{Fe})$ that is approved for iron deficiency treatment and currently investigated as an MRI contrast agent. The light scattering of control macrophages, nanoparticle-labeled macrophages $(2,000,000$ in $500 \mu \mathrm{L})$ and nanoparticle suspensions was measured in synchronous wavelength scan mode using a fluorescence spectrophotometer. For OCT analyses, pellets of 8,000,000 non-labeled, VSOP-labeled and ferumoxytol-labeled RAW 264.7 macrophages were imaged and analyzed on an OPTISTM OCT imaging system.

Results: Incubation with 1 and $2 \mathrm{mM}$ VSOP resulted in uptake of $7.1 \pm 1.5$ and $12 \pm 1.5 \mathrm{pg} \mathrm{Fe}$ per cell, which increased the backscattering of the macrophages in spectrophotometry 2.5- and 3.6-fold, whereas incubation with $8.9 \mathrm{mM}$ Fe ferumoxytol resulted in uptake of $6.6 \pm 2 \mathrm{pg} \mathrm{Fe}$ per cell, which increased the backscattering 1.5-fold at $700 \mathrm{~nm}$. In contrast, backscattering of non-clustered nanoparticles in suspension was negligible. Accordingly, OCT imaging could visualize significantly increased backscattering and signal attenuation of nanoparticle-labeled macrophages in comparison with controls.

Conclusion: We conclude that VSOP and, to a lesser extent, ferumoxytol increase light scattering and attenuation when taken up by macrophages and can serve as a multimodal imaging probe for MRI and OCT to improve macrophage detection in atherosclerotic plaques by OCT in the future.

Keywords: intravascular, inflammation, vulnerability, multimodal imaging, optical coherence tomography, magnetic resonance imaging

\section{Introduction}

Optical coherence tomography (OCT) has become a core intravascular imaging modality in clinical practice. The extraordinary high-image resolution allows to discriminate several important characteristics of atherosclerotic plaques that are associated with severe acute cardiovascular events such as myocardial infarction and stroke. Although many important features of plaques can be distinguished by OCT,
Correspondence: Eyk Schellenberger Department of Radiology, CharitéUniversitätsmedizin Berlin, Charitéplatz I, 10117 Berlin, Germany Tel +4930450539013 Email eyk.schellenberger@charite.de (c) (1) (-) 2018 Ariza de Schellenberger et al. This work is published and licensed by Dove Medical Press Limited. The full terms of this license are available at https://www.dovepress.com/terms.php cc) ${ }_{\mathrm{BY}} \mathrm{NC}$ and incorporate the Creative Commons Attribution - Non Commercial (unported, v3.0) License (http://creativecommons.org/licenses/by-nc/3.0/). By accessing the work you hereby accept the Terms. Non-commercial uses of the work are permitted without any further permission from Dove Medical Press Limited, provided the work is properly attributed. For permission for commercial use of this work, please see paragraphs 4.2 and 5 of our Terms (https://www.dovepress.com/terms.php). 
the assessment of inflammation, for example, by imaging of macrophages within the plaque, is still challenging. ${ }^{1,2}$

Several superparamagnetic iron oxide nanoparticles (NPs) that serve as contrast agents for magnetic resonance imaging (MRI) have shown accumulation in plaque macrophages. Macrophages are an important indicator for the inflammatory activity and vulnerability of atherosclerotic lesions. One disadvantage of most sterically stabilized NPs is their slow target accumulation of 24 hours and longer. For example, ferumoxytol (Feraheme ${ }^{\circledR}$; AMAG Pharmaceuticals, Inc., Waltham, MA, USA), which is clinically approved for iron replacement therapy, needs 2 days for substantial accumulation in atherosclerotic plaques, as required for good contrast in MRI, and peaks after 3 days. ${ }^{3}$ In contrast, electrostatically stabilized citrate-coated very small iron oxide particles (VSOP) that were already in clinical testing for magnetic resonance (MR) angiography ${ }^{4,5}$ accumulate initially in endothelial cells ${ }^{6}$ and later in the macrophages of atherosclerotic plaques. ${ }^{7}$ Thus, VSOP allow MR angiography and MRI of plaque inflammation in $<3$ hours.

Interestingly, transmission electron microscopy (TEM) revealed that the uptake of VSOP into the atherosclerotic plaques leads to the formation of large NP aggregates in the phagolysosomes of endothelial cells and macrophages. ${ }^{7}$ This let us hypothesize that these distribution patterns could cause sufficient light scattering to be visualized by OCT.

Consequently, we incubated a macrophage cell line with VSOP or ferumoxytol NPs, measured changes of the light backscattering signal in suspension by spectrophotometry, and compared the OCT signals of cell pellets with the OCT signals of NPs in suspension.

\section{Materials and methods TEM}

TEM imaging of VSOP accumulated in macrophages of atherosclerotic plaques was done as described elsewhere. ${ }^{7}$ The animal experiments were approved by the local animal welfare committee (LAGeSo Berlin; license G0168/09) and were done in accordance with the "Tierschutz-Versuchstierv erordnung" of the Federal Ministry of Justice and Consumer Protection. In brief, starting at the age of 8 weeks, male apoE $^{-/-}$mice (Taconic, Lille Skensved, Denmark) were fed with a Western diet $(0.21 \%$ cholesterol and $21 \%$ fat from lard; Altromin) for a duration of 16 weeks. After that, VSOP were applied intravenously ( $500 \mu \mathrm{mol} \mathrm{Fe} / \mathrm{kg}$ body weight). Three hours after administration, the mice were anesthetized using isoflurane and perfused with $20 \mathrm{~mL}$ cacodylate buffer $(0.1 \mathrm{M}$; $\mathrm{pH} 7.2$ ) to remove all the blood for subsequent tissue fixation with $20 \mathrm{~mL}$ of $2.5 \%$ glutaraldehyde in cacodylate buffer.
Heart, aorta and descending vessels were dissected and placed in $2.5 \%$ glutaraldehyde in cacodylate buffer at $4^{\circ} \mathrm{C}$ for further fixation. Samples were dehydrated in ethanol and embedded in Epon embedding media (Serva) and cut in ultra-thin sections $(70 \mathrm{~nm})$. The sections were analyzed unstained on a Zeiss EM906 scanner (Carl Zeiss Meditec AG, Jena, Germany).

\section{Cell culture and NP labeling}

The macrophage cell line RAW 264.7 was purchased from ATCC Cell biology Collection (Promochem LGC, Molsheim, France). This cell line is derived from mice peritoneal macrophages transformed by Abelson Murine Leukemia Virus. Cells were cultured in DMEM (ATCC) supplemented with 10\% FBS (Thermo Fisher Scientific, Waltham, MA, USA) and $1 \%$ penicillin-streptomycin (penicillin 10,000 units $/ \mathrm{mL}$ and streptomycin $10 \mathrm{mg} / \mathrm{mL}$; Sigma-Aldrich Co., St Louis, $\mathrm{MO}$, USA) and incubated at $37^{\circ} \mathrm{C}$ in a $5 \%$ carbon dioxide humidified atmosphere. Cells were regularly passaged until they reached around $80 \%$ confluence, and the medium was changed every 2 days.

For NP uptake, macrophages were cultured $(100,000$ cells $/ \mathrm{cm}^{2}$ in $75 \mathrm{~cm}^{2}$ tissue culture flasks) overnight to allow cell synchronization. On the following day, growth medium was removed and cells were gently washed with PBS before adding the NP solution in DMEM (ATCC) without phenol red supplemented with 1\% FBS (Thermo Fisher Scientific). Cells were incubated with VSOP ( $1 \mathrm{mM}$ and $2 \mathrm{mM}$ Fe final concentration) or ferumoxytol (Feraheme; $8.9 \mathrm{mM} \mathrm{Fe}$ ) for 24 hours at $37^{\circ} \mathrm{C}$ in a $5 \%$ carbon dioxide humidified atmosphere. Non-bound NPs were removed by washing three times with PBS, followed by centrifugation of the cells (1,000 rpm for 5 minutes) and passage into a $25 \mathrm{~cm}^{2}$ cell culture flasks at 100,000 cells $/ \mathrm{cm}^{2}$. Overnight cell recovery and further internalization of NPs were allowed under cell growth conditions before cell pellet collection.

\section{Cell phantoms for OCT measurements}

For OCT acquisition, the test samples were centrifuged in $0.2 \mathrm{~mL}$ transparent thin-walled polypropylene PCR tubes (Thermo Fisher Scientific). These samples contained $8 \times 10^{6}$ macrophages (RAW 264.7) equivalent to a volume of $10 \mu \mathrm{L}$. They were grouped as follows: 1) non-labeled cells used as control; 2) cells incubated with VSOP at $1 \mathrm{mM} \mathrm{Fe;} \mathrm{3)} \mathrm{cells}$ incubated with VSOP at $2 \mathrm{mM}$ Fe and 4) cells incubated with ferumoxytol at $8.9 \mathrm{mM} \mathrm{Fe}$.

To study the effect of NP aggregation inside the cells on optical backscattering and attenuation, two additional control samples containing high concentrated stock solutions of NP in suspension without cells were measured for 
comparison: 5) VSOP 0.5 M Fe in suspension (10 $\mu \mathrm{L})$ and 6) ferumoxytol $0.54 \mathrm{M} \mathrm{Fe}$ in suspension $(10 \mu \mathrm{L})$.

\section{Cell suspensions for light scattering measurements}

For light spectroscopy measurements, RAW 264.7 macrophages were incubated with $1 \mathrm{mM} \mathrm{Fe}, 2 \mathrm{mM}$ VSOP and 8.9 $\mathrm{mM}$ ferumoxytol as previously described. Cell suspensions contained $2 \times 10^{6}$ cells in $500 \mu \mathrm{L}$ PBS pH 7.4. The cell-free $\mathrm{NP}$ suspensions were prepared in water at $1 \mathrm{mM} \mathrm{Fe}$ for both VSOP and ferumoxytol.

\section{Iron quantification}

Fractions of cells ( $\mathrm{n}=4$ with 50,000 in each) that were used for OCT measurements were measured for their NP uptake using the colorimetric phenanthroline iron quantification method. ${ }^{8}$ The method was adapted for cell pellets stored at $-20^{\circ} \mathrm{C}$. Cell pellets were disrupted by 1 hour ultrasound exposure and the incorporated iron was dissolved by adding $5 \mu \mathrm{L}$ of concentrated $\mathrm{HCl}$. Dissolved iron in $\mathrm{HCl}$ was diluted in water (1:50) and treated at a ratio 2:7:1 with phenanthroline and hydroxylamine hydrochloride for 15 minutes at room temperature. The extinctions of the colorimetric reactions of the samples and of iron standards were measured photometrically at $510 \mathrm{~nm}$ and a linear standard curve fit was used to determine the iron concentrations. The iron concentrations were divided by the cell numbers to calculate the NP uptake per cell (pg Fe/cell).

\section{Light spectroscopy measurements}

The scattering light intensities of control macrophages, NPlabeled macrophages and NP suspensions were measured as wavelength scan (synchronous scan mode) using an F-7000 fluorescence spectrophotometer (Hitachi Ltd, Tokyo, Japan). With this method, the excitation wavelength is equal to the emission wavelength. The scattered light intensity was measured according to the manufacturer's instructions for the complete wavelength range of the device $(200-900 \mathrm{~nm}$, $240 \mathrm{~nm} / \mathrm{min}$, excitation slit $5.0 \mathrm{~nm}$, emission slit $5.0 \mathrm{~nm}$, photomultiplier voltage $400 \mathrm{~V}$, response $2 \mathrm{~ms}$ ).

The light absorption measurements of VSOP and ferumoxytol were done using a Specord ${ }^{\circledR} 205$ Spectrophotometer (Analytik Jena AG, Jena, Germany) at $0.2 \mathrm{mM} \mathrm{Fe}$ according to the manufacturer's instructions. The results were compared and visualized using GraphPad Prism 5.0 Mac (GraphPad Prism Software).

\section{OCT imaging}

OCT imaging was performed using a Dragonfly ${ }^{\mathrm{TM}}$ optical catheter (St Jude Medical, Inc., Little Canada, MN, USA) connected to an OPTIS ${ }^{\text {TM }}$ OCT imaging system (St Jude Medical, Inc.) according to the manufacturer's instructions. Sixteen OCT imaging pullbacks were done of phantom pairs with different combinations of macrophages loaded with VSOP 1 and VSOP 2, ferumoxytol or empty cells as control and of VSOP and ferumoxytol in suspension. The cell phantoms were analyzed for the signal backscatter and attenuation values using the Tissue Properties tool of the ILUMIEN"T OPTIS ${ }^{\text {TM }}$ Offline Review Workstation (Tissue Properties Supplement; St Jude Medical, Inc.). From each cell phantom, five sections were analyzed by half automatic selection of an ROI around the cells and measuring attenuation and backscatter values with Tissue Properties tool (Figure S1). ROI parts with diminishing signal in the periphery below the software's threshold were excluded by the software. The stock solution phantoms of $10 \mu \mathrm{L}$ VSOP and $10 \mu \mathrm{L}$ ferumoxytol (both $0.5 \mathrm{M} \mathrm{Fe}$ ) did not generate sufficient signal to select and analyze ROIs with the Tissue Properties tool. The values were averaged, and the results were displayed and analyzed employing a one-way ANOVA with Tukey's multiple comparison test of GraphPad Prism 5.0 Mac (GraphPad Prism Software).

\section{Results}

\section{Labeling of macrophages with iron oxide NPs}

By exploiting the inherent contrast, the exemplary, unstained TEM image of Figure 1 visualizes the typical intracellular uptake of VSOP into macrophages of atherosclerotic plaques after intravenous application. The micrograph demonstrates representatively the formation of NP clusters in phagolysosomes. The uptake of iron oxide NPs by RAW 264.7

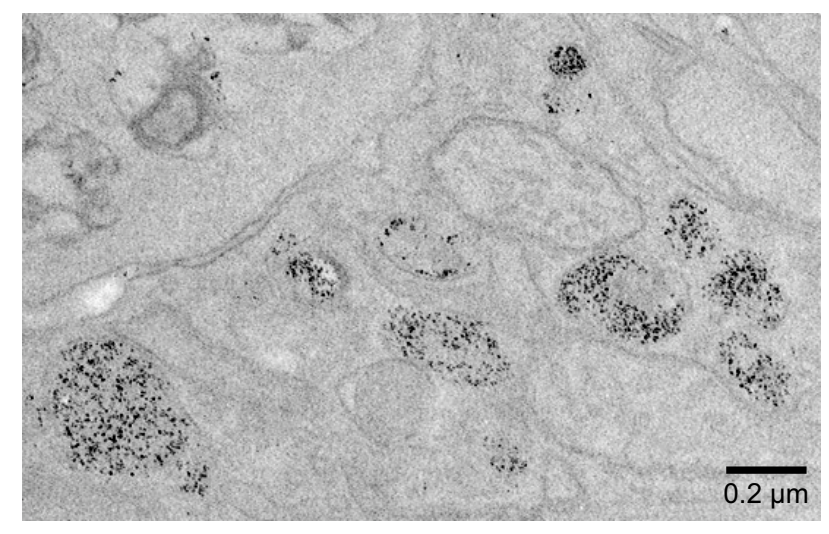

Figure I TEM of VSOP in atherosclerotic plaques.

Notes: After intravenous injection, VSOP accumulate in atherosclerotic plaques of $\mathrm{ApoE}^{-/-}$mice as aggregates in phagolysosomal structures of macrophages as shown here, as well as in endothelial cells (not shown). ${ }^{7}$ The small iron oxide cores themselves provide the native contrast for TEM of unstained tissue sections and are separately distinguishable.

Abbreviations: TEM, transmission electron microscopy; VSOP, very small iron oxide particles. 

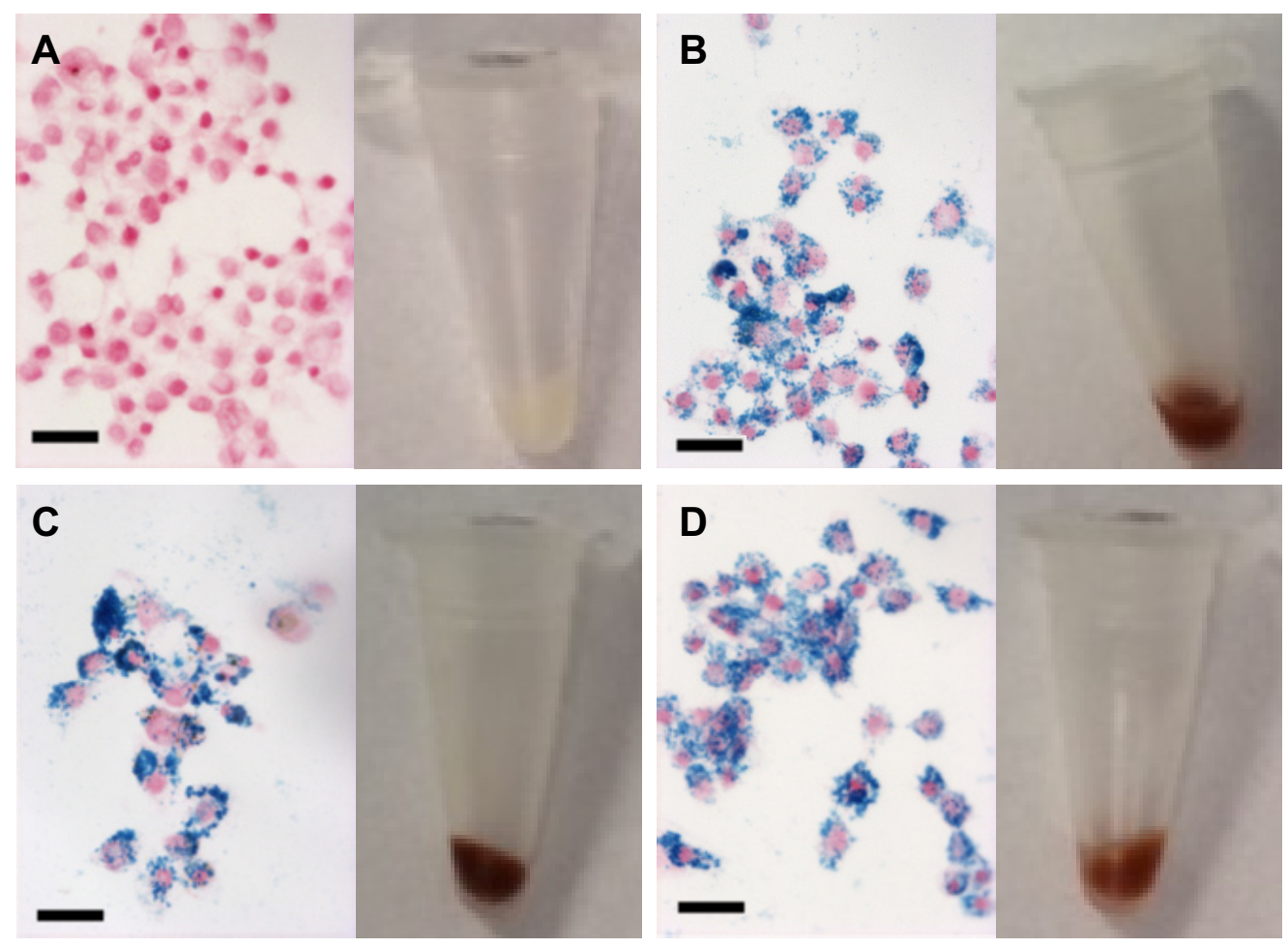

Figure 2 Cell phantoms of macrophages labeled with NPs as measured with OCT and Prussian blue iron staining.

Notes: White cell pellets correspond to non-labeled RAW 264.7 macrophages (A) in comparison to brown cells pellets after NP uptake on incubation of macrophages with (B) I mM Fe VSOP, (C) 2 mM Fe VSOP and (D) $8.9 \mathrm{mM}$ Fe ferumoxytol. All cells show intracellular NP uptake (B-D) and preserved cell morphology and viability in comparison with non-labeled cells (A). All scale bars correspond to $50 \mu \mathrm{m}$.

Abbreviations: NP, nanoparticle; OCT, optical coherence tomography; VSOP, very small iron oxide particles.

macrophages were visualized by Prussian blue iron staining (Figure 2). Incubations with $1 \mathrm{mM} \mathrm{Fe} \mathrm{VSOP} \mathrm{(concentration} \mathrm{1)}$ and $2 \mathrm{mM}$ Fe VSOP (concentration 2) were more effective than incubation with $8.9 \mathrm{mM}$ Fe ferumoxytol and resulted in NP uptakes of $7.1 \pm 1.5,12 \pm 1.5$ and $6.6 \pm 2$ pg Fe per cell, respectively. Cell phantoms loaded with iron oxide particles as measured by OCT were brown in contrast to the white color of the control cells.

\section{Light scattering by spectroscopy}

NPs (VSOP and ferumoxytol) in suspension did not show significant light scattering, especially in the near-infrared range (700-900 nm wavelength), when measured by spectrophotometry (Figure 3). However, when similar amounts of NPs were taken up by the macrophages, VSOP and ferumoxytol increased the scattering of these cells substantially: the scattering signal of VSOP-labeled macrophages with 7.1 \pm 1.5 pg Fe per cell (VSOP 1) and $12 \pm 1.5$ pg Fe per cell (VSOP 2) at $700 \mathrm{~nm}$ was 2.4 -fold (214 arbitrary units [AU]) and 3.6-fold (322 AU) higher than that of unlabeled macrophages (90 AU; Figure 3 ) and $>100$-fold higher than the scattering produced by VSOP in suspension (1.82 AU) at a comparable concentration (Figure 3A, C and E). But on incubation with ferumoxytol at a higher concentration $(8.9 \mathrm{mM} \mathrm{Fe})$, the cellular uptake of ferumoxytol was lower $(6.6 \pm 2 \mathrm{pg}$ Fe per cell) and it caused a scattering signal of $129.8 \mathrm{AU}$ at $700 \mathrm{~nm}$, representing a 1.4-fold increase compared to unlabeled macrophages (Figure 3B, D and F). Conversely, at wavelengths below $400 \mathrm{~nm}$, the scattering signal of NP-labeled cells was lower than the scattering of unlabeled cells, which fits to the high absorption of NP in suspension in the ultraviolet range that becomes negligible in the near-infrared spectrum, that is, above $700 \mathrm{~nm}$.

\section{OCT imaging}

In accordance with the spectroscopy measurements, Figure 4 shows that cell phantoms of macrophages that took up NP had a higher backscattering signal and a substantially higher attenuation in OCT imaging compared to unlabeled macrophages. The increase in backscattering signals was significantly higher for cells labeled with VSOP concentration $1(5.82 \pm 0.27 \mathrm{AU}$; $P<0.001)$ and VSOP $2(6.07 \pm 0.12 \mathrm{AU} ; P<0.001)$ in comparison to control cells ( $5.49 \pm 0.12 \mathrm{AU})$, whereas ferumoxytol that is less effectively taken up by the macrophages did not cause a significant increase of scattering (5.68 $\pm 0.22 \mathrm{AU}$; ns), as shown in Figure 5A. In contrast, the increase in signal 

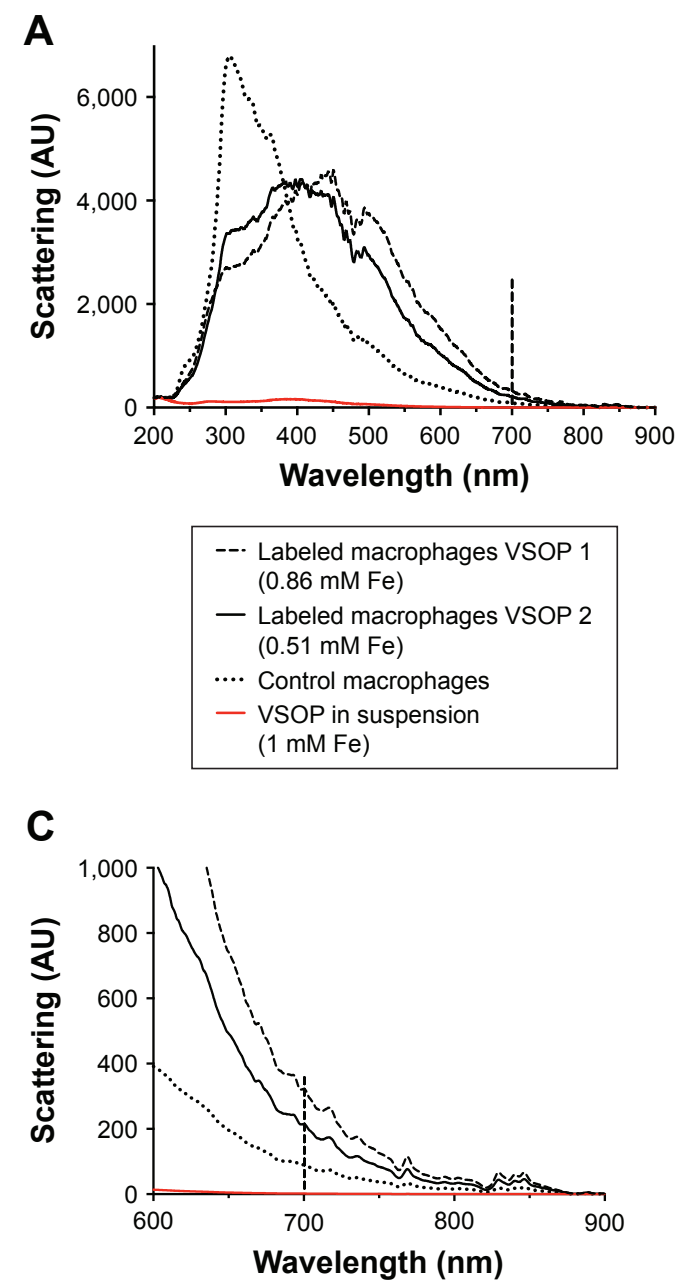

$\mathbf{E}$

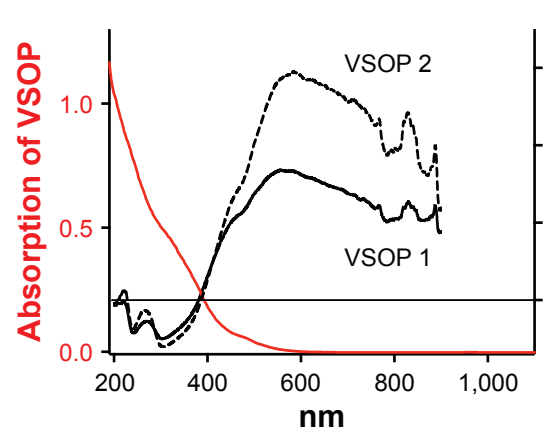

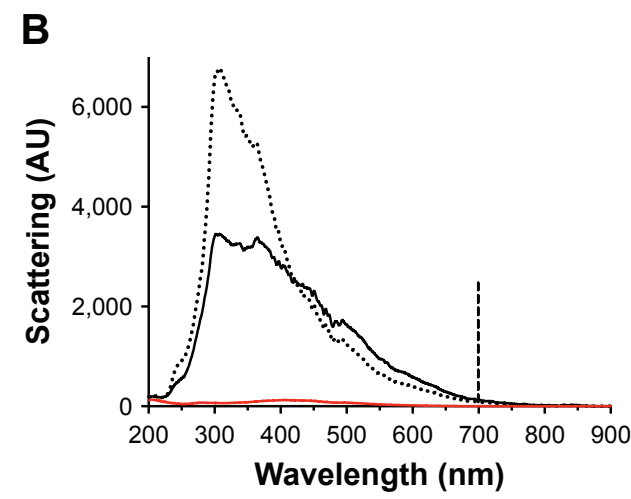
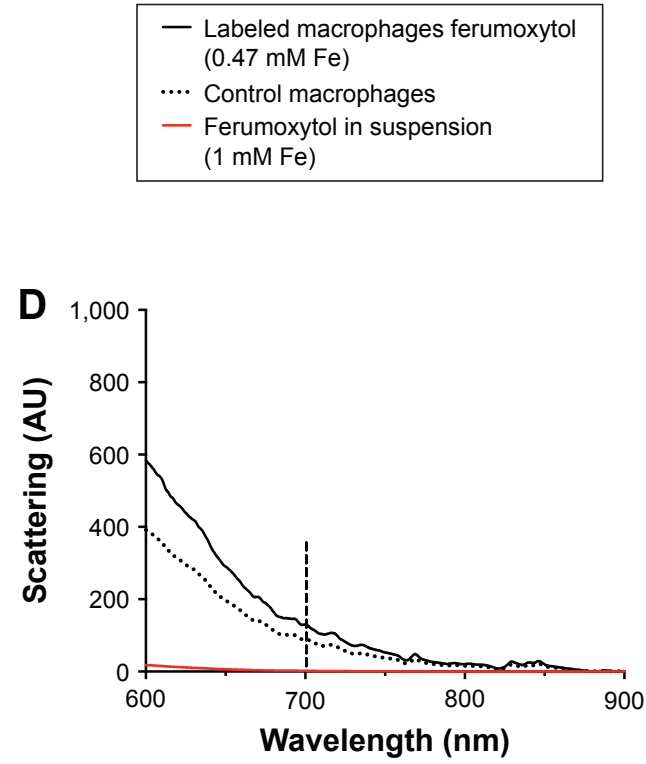

$\mathbf{F}$

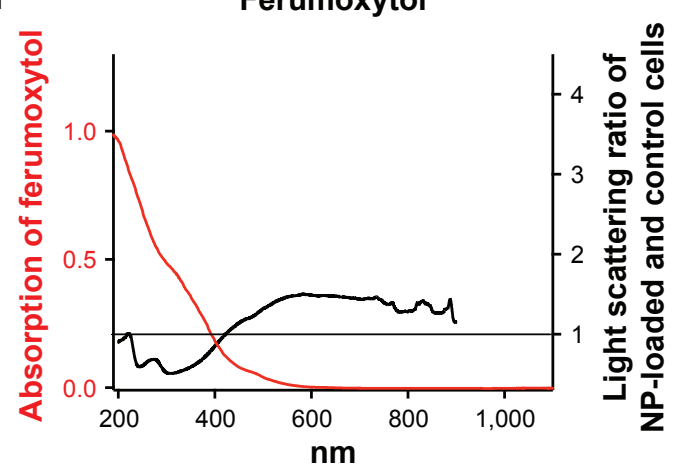

Figure 3 Spectroscopic analysis: light scattering of NP-loaded cells, control cells (RAW 264.7 macrophage cell line) and NP in suspension, depending on the wavelength. Notes: VSOP (left) and ferumoxytol (right) in suspension demonstrate only minimal light scattering (A, B) (red lines), especially above 600 nm (C, D is an enlargement of A, B). The control macrophages scatter especially below $450 \mathrm{~nm}$ (dotted black lines). Suspensions of NP-loaded cells (calculated concentrations for $2 \times 10^{6}$ cells per $500 \mu \mathrm{L}$ for VSOP I $7 . I \pm I .5 \mathrm{pg}$ Fe/cell; VSOP $2 \mathrm{I} 2 \pm \mathrm{I} .5 \mathrm{pg}$ Fe/cell; ferumoxytol $6.6 \pm 2 \mathrm{pg}$ Fe/cell) in final iron concentrations comparable to the NP suspensions increase the scattered light substantially, especially at wavelengths above $450 \mathrm{~nm}$, including the near-infrared region ( $>700 \mathrm{~nm}$; C, D). The absorption spectra of the NPs in suspension are given in panels (E) and (F) (red lines), running inversely to the light scattering ratio of NP-loaded vs unloaded macrophages (black lines). The high light absorption of the NP in the UV range might explain the lower scattering signal of the NP-loaded macrophages below $400 \mathrm{~nm}$ wavelength. Abbreviations: AU, arbitrary units; NP, nanoparticle; UV, ultraviolet; VSOP, very small iron oxide particles.

attenuation was significant for all cell phantoms with NP uptake (control cells: $3.12 \pm 0.42 \mathrm{AU}$; VSOP 1: $5.30 \pm 0.32 \mathrm{AU}$; VSOP 2: $6.63 \pm 0.43 \mathrm{AU}$; ferumoxytol: $4.56 \pm 0.13 \mathrm{AU}$; all $P<0.001$; Figure 5B).
As for the spectroscopy measurements, stock solutions of NP in suspension (both $\sim 0.5 \mathrm{M} \mathrm{Fe}$ ) did not cause any relevant OCT signal despite higher NP concentrations, compared to the cell phantoms. In fact, the OCT signal 


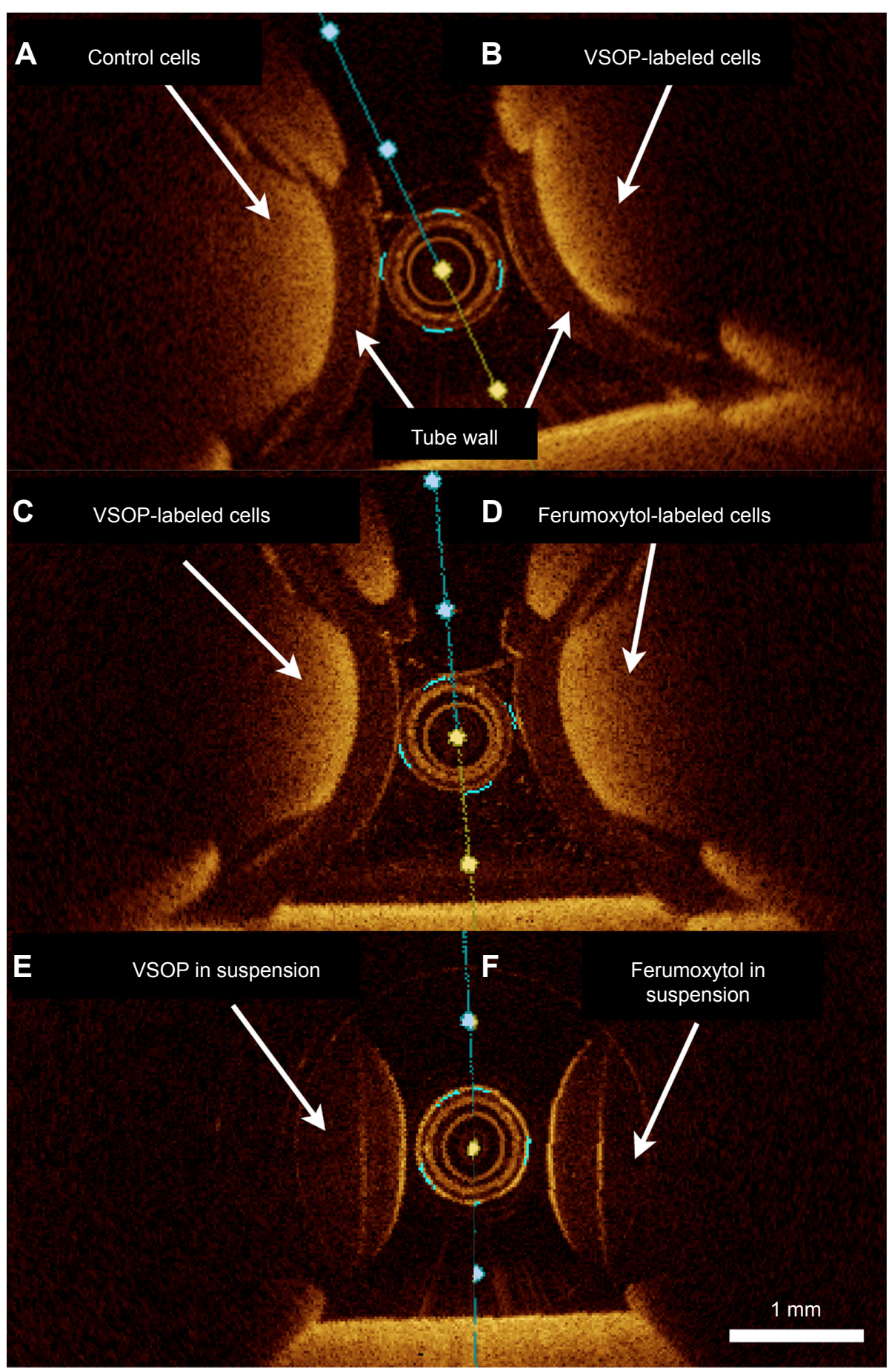

Figure 4 OCT images of iron oxide NP-labeled macrophages.

Notes: Unlabeled RAW 264.7 cell phantoms (A), labeled with VSOP at concentration 2 ( $12 \pm I .5$ pg Fe/cell) (B), labeled with VSOP at concentration I (7.I \pm I.5 pg Fe/cell) (C) and labeled with ferumoxytol $(6.6 \pm 2 \mathrm{pg}$ Fe/cell) (D). In comparison to the unlabeled cells, NP labeling increased the OCT signal of macrophages and induced stronger attenuation. In contrast, VSOP (E) and ferumoxytol (F) in suspension (no cells) with slightly higher NP concentrations than the cell phantoms did not generate visible OCT signals, which is in accordance to the spectroscopy measurements (Figure 3).

Abbreviations: NP, nanoparticle; OCT, optical coherence tomography; VSOP, very small iron oxide particles.

was so low that the half automatic selection of a measurement ROI with the Tissue Property tool was not possible, and thus, no attenuation or backscattering values for the NP suspension phantoms could be determined with the software.

\section{Discussion}

In the present study, we demonstrated that iron oxide NPs (VSOP and ferumoxytol) in suspension cause neither relevant backscattering in spectroscopy in the wavelength range relevant for OCT nor OCT image signals. However, they 

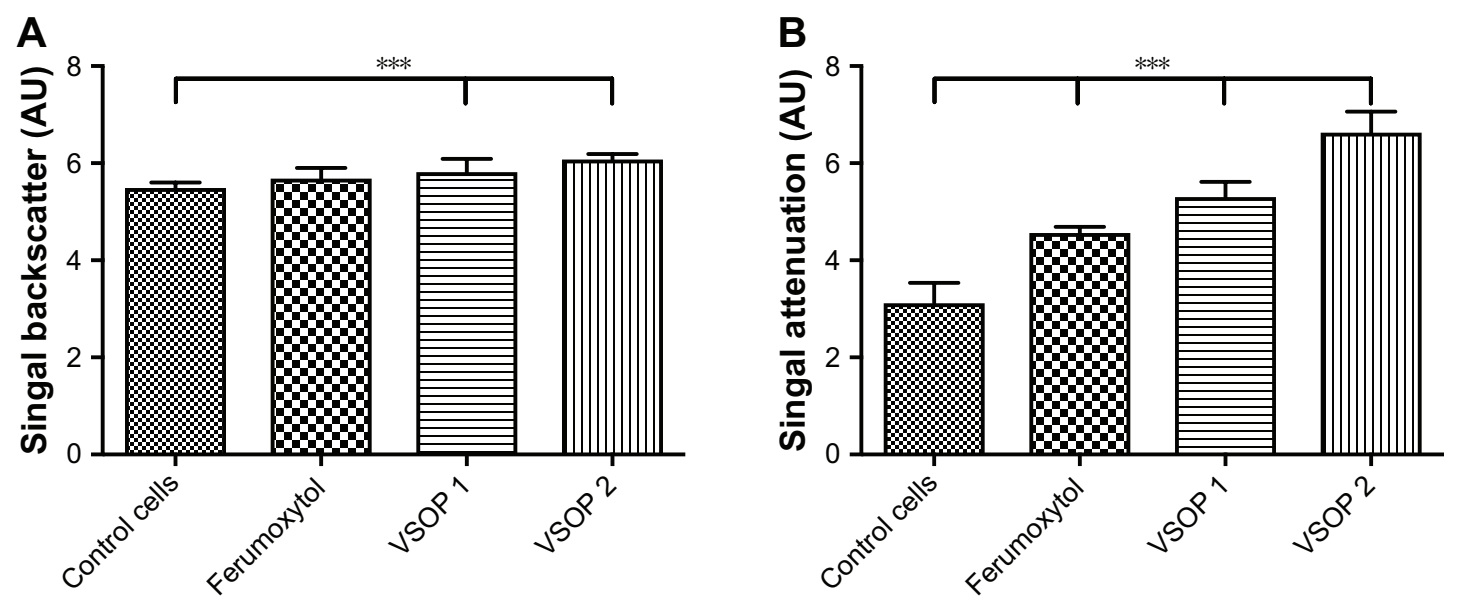

Figure 5 Analysis of OCT signals of RAW 264.7 cell phantoms.

Notes: $* * * P<0.01$. Averaged OCT signal backscatter $(\mathbf{A})$ and signal attenuation $(\mathbf{B})$ of cell phantoms (Figure 4 ) from seven pullback measurements and five sections each. The NP suspensions of VSOP and ferumoxytol (without cells) did not generate sufficient OCT signal to be analyzed by the OCT software tool. NP uptake in the macrophages resulted in higher OCT backscattering signals (significant for VSOP concentration I and 2, P<0.0I) and strong signal attenuation of the cell phantoms (significant for VSOP and ferumoxytol, $P<0.01$ ). Statistical analysis: one-way ANOVA with Tukey's multiple comparison test using GraphPad Prism 5.0 Mac (GraphPad Prism Software). Abbreviations: AU, arbitrary units; NP, nanoparticle; OCT, optical coherence tomography; VSOP, very small iron oxide particles.

substantially increased the backscattering in spectroscopy and backscattering as well as attenuation in OCT imaging when taken up by macrophages. This effect could be related to the clustering of the NPs once they are taken up into phagolysosomes of the macrophages (Figure 1)..$^{7,9,10}$ An explanation could be that when the NP size is substantially smaller (VSOP $\sim 8 \mathrm{~nm}$, ferumoxytol $17-31 \mathrm{~nm}$ ) than the wavelength of light (OCT wavelength around 1,000 nm), the intensity of the light scattering is proportional to the sixth power of particle size (Rayleigh theory). ${ }^{11} \mathrm{NP}$ uptake into phagolysosomes of macrophages results in NP aggregates that can serve as substantially enlarged scatterers compared to the individual NPs in suspension, thereby increasing light backscattering and attenuation as seen in spectroscopic light scattering measurements and OCT imaging. The NP uptake of the cells in this study was relatively high, but we have shown ex vivo by quantitative laser ablation inductively coupled plasma mass spectrometry in a previous study that VSOP do accumulate in atherosclerotic plaques in very high local concentrations (eg, local tissue particle concentrations of $50 \mathrm{mM} \mathrm{Fe}$ ). ${ }^{12}$

Importantly, the OCT measurements were done with an OCT system and settings as used in the clinics. Considering the strongest increase of the backscattering signal at $\sim 600 \mathrm{~nm}$ for VSOP that is below the wavelength range of the OCT system, the OCT sensitivity for NPs could potentially even be improved by modifications of the OCT system and measurement protocols to exploit these properties.

It is important to highlight that macrophages are already distinguishable in OCT imaging by their pronounced attenuation and backscattering in comparison to the other constituents of atherosclerotic plaques, even though it is difficult. ${ }^{13}$
Thus, the higher attenuation and backscattering caused by NP uptake by the macrophages is in addition to the intrinsic higher OCT signal of these cells and could, therefore, substantially improve their identification in vivo by OCT.

\section{Limitations}

The OCT images of the cell pellets might appear somewhat noisy because the cell pellets do not have structures like arterial walls have and the cell pellets are, in general, very densely packed, explaining that no individual cells are discernible. Another important aspect to consider is the necessity for the OCT light to penetrate several optical boundaries (catheter/ air/plastic/cell pellet) that are less and different in vivo (catheter/blood/vessel wall). Certainly, the in vitro results need to be confirmed by future in vivo studies with animals that allow OCT imaging.

Moreover, the OCT system was an unmodified clinical device. Due to the distinct optical properties of macrophages after NP uptake (see Light scattering by spectroscopy section), future modifications of the OCT system, imaging procedure and post-processing have a great potential to further enhance detection of the NP-loaded cells.

\section{Conclusion}

In this in vitro study, we demonstrated that small NPs significantly increase the backscattering and OCT signal of macrophages, once they are taken up and cluster in phagolysosomes. Previous in vivo studies have shown that these NPs are taken up by plaque macrophages and allow effective MR imaging of atherosclerotic plaques. Therefore, we conclude that the OCT evaluation of inflammatory activity 
in atherosclerotic plaques could be substantially improved by NP-enhanced OCT imaging of macrophages.

\section{Acknowledgment}

We thank the group of Prof M Taupitz for supplying the VSOP.

\section{Disclosure}

The authors report no conflicts of interest in this work.

\section{References}

1. Otsuka F, Joner M, Prati F, Virmani R, Narula J. Clinical classification of plaque morphology in coronary disease. Nat Rev Cardiol. 2014; 11(7):379-389.

2. Di Vito L, Yoon JH, Kato K, et al; COICO group (Consortium of Investigators for Coronary OCT). Comprehensive overview of definitions for optical coherence tomography-based plaque and stent analyses. Coron Artery Dis. 2014;25(2):172-185.

3. Herborn CU, Vogt FM, Lauenstein TC, et al. Magnetic resonance imaging of experimental atherosclerotic plaque: comparison of two ultrasmall superparamagnetic particles of iron oxide. J Magn Reson Imaging. 2006;24(2):388-393.

4. Wagner M, Wagner S, Schnorr J, et al. Coronary MR angiography using citrate-coated very small superparamagnetic iron oxide particles as blood-pool contrast agent: initial experience in humans. J Magn Reson Imaging. 2011;34(4):816-823.
5. Taupitz M, Wagner S, Schnorr J, et al. Phase I clinical evaluation of citrate-coated monocrystalline very small superparamagnetic iron oxide particles as a new contrast medium for magnetic resonance imaging. Invest Radiol. 2004;39(7):394-405.

6. Poller WC, Ramberger E, Boehm-Sturm P, et al. Uptake of citratecoated iron oxide nanoparticles into atherosclerotic lesions in mice occurs via accelerated transcytosis through plaque endothelial cells. Nano Res. 2016;9(11):3437-3452.

7. Scharlach C, Kratz H, Wiekhorst F, et al. Synthesis of acid-stabilized iron oxide nanoparticles and comparison for targeting atherosclerotic plaques: evaluation by MRI, quantitative MPS, and TEM alternative to ambiguous Prussian blue iron staining. Nanomedicine. 2015;11(5): 1085-1095.

8. Saywell LG, Cunningham BB. Determination of iron: colorimetric o-phenanthroline method. Anal Chem. 1937;9:67-69.

9. Grottone GT, Loureiro RR, Covre J, Rodrigues EB, Gomes JÁ. ARPE-19 cell uptake of small and ultrasmall superparamagnetic iron oxide. Curr Eye Res. 2014;39(4):403-410.

10. Kim SJ, Lewis B, Steiner MS, Bissa UV, Dose C, Frank JA. Superparamagnetic iron oxide nanoparticles for direct labeling of stem cells and in vivo MRI tracking. Contrast Media Mol Imaging. 2016;11:55-64.

11. Gregory J. Monitoring particle aggregation processes. Adv Colloid Interface Sci. 2009;147-148:109-123.

12. Scharlach C, Müller L, Wagner S, et al. LA-ICP-MS allows quantitative microscopy of europium-doped iron oxide nanoparticles and is a possible alternative to ambiguous Prussian blue iron staining. J Biomed Nanotechnol. 2016;12(5):1001-1010.

13. Sinclair H, Bourantas C, Bagnall A, Mintz GS, Kunadian V. OCT for the identification of vulnerable plaque in acute coronary syndrome. JACC Cardiovasc Imaging. 2015;8(2):198-209. 


\section{Supplementary material}

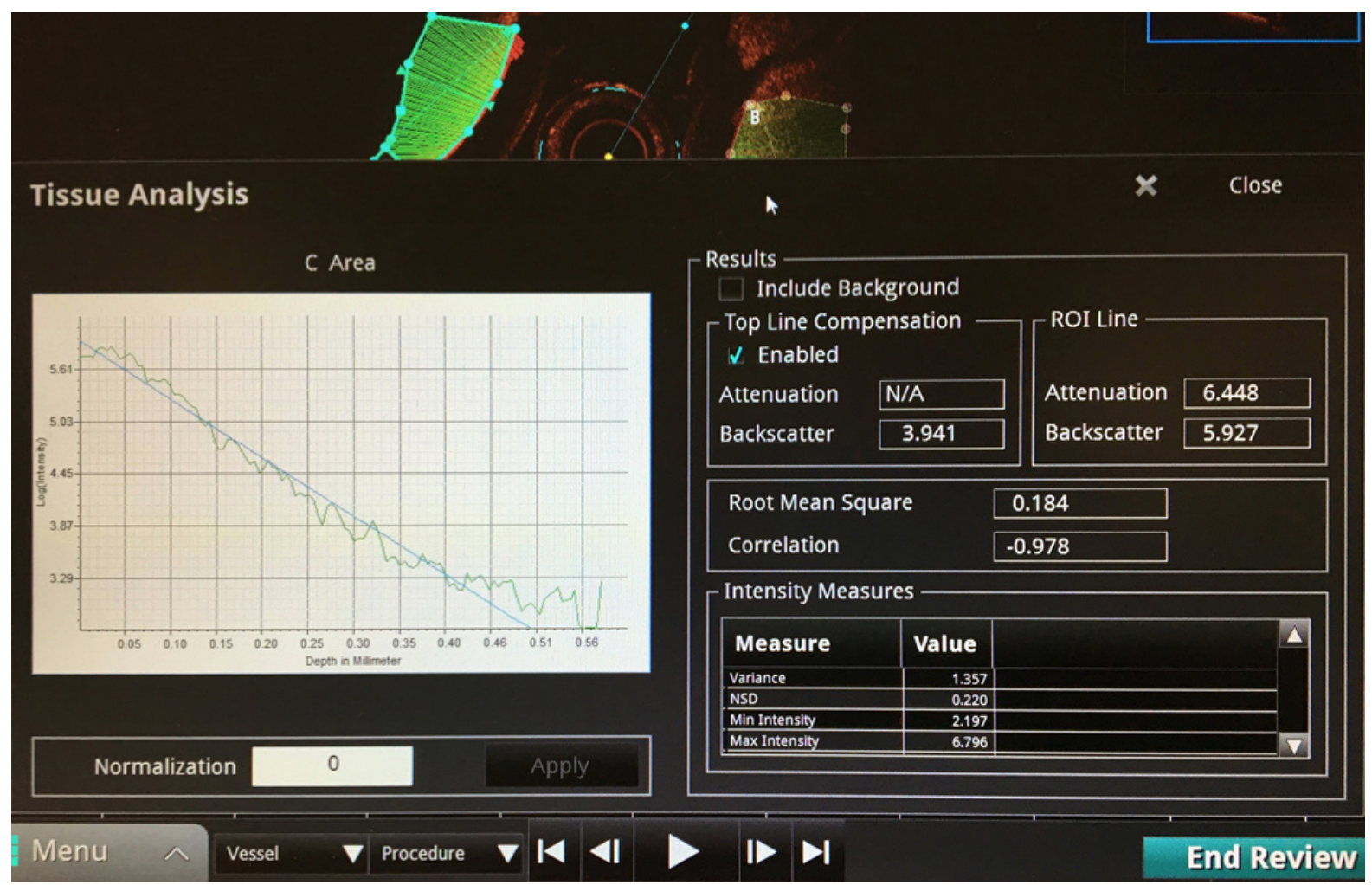

Figure SI Example for quantification of the OCT images with the ILUMIENTM OPTISTM Offline Review Workstation Tissue Properties Supplement.

Notes: The ROls were drawn in the region of the macrophage cells in the reaction tubes in a semi-automatic way by selecting ROls beginning at the bottom of the macrophage cell pellets. The software reduced the ROI at the distant side when reaching a lower signal threshold. The values of Attenuation and Backscatter (ROI Line) were used and averaged from five sections of each pellet of the OCT pullbacks.

Abbreviations: OCT, optical coherence tomography; NSD, normalized standard deviation.

\section{Publish your work in this journal}

The International Journal of Nanomedicine is an international, peerreviewed journal focusing on the application of nanotechnology in diagnostics, therapeutics, and drug delivery systems throughout the biomedical field. This journal is indexed on PubMed Central, MedLine, CAS, SciSearch ${ }^{\circledR}$, Current Contents ${ }^{\circledR} /$ Clinical Medicine,
Journal Citation Reports/Science Edition, EMBase, Scopus and the Elsevier Bibliographic databases. The manuscript management system is completely online and includes a very quick and fair peer-review system, which is all easy to use. Visit http://www.dovepress.com/ testimonials.php to read real quotes from published authors.

\footnotetext{
Submit your manuscript here: http://www.dovepress.com/international-journal-of-nanomedicine-journal
} 